\title{
Vision of the Arc for Quality Documentation and for Closed Loop Control of the Welding Process
}

\author{
Morten Kristiansen and Ewa Kristiansen \\ Department of Mechanical and Manufacturing Engineering, Aalborg, Denmark \\ Email: \{morten, ewa $@$ @m-tech.aau.dk \\ Casper Houmann Jensen \\ Aalborg Engineering, Aalborg, Denmark \\ Email: chj@aalborg-engineering.dk \\ René Slot Christensen \\ Novo Nordisk, Hillerød, Denmark \\ Email: rslc@novonordisk.com
}

\begin{abstract}
For gas metal arc welding a vision system was developed, which was robust to monitor the position of the arc. The monitoring documents the welding quality indirectly and a closed loop fuzzy control was implemented to control an even excess penetration. For welding experiments on a butt-joint with a V-groove with varying root gapthe system demonstrated increased welding quality compared to the system with no control. The system was implemented with a low cost vision system, which makes the system interesting to apply in industrial welding automation systems.
\end{abstract}

Index Terms - Gas metal arc welding, fuzzy control, closed loop control, welding documentation, vision, automation

\section{INTRODUCTION}

The industry is interested in solutions for automation of the arc welding process, where productions costs can be reduced, stability of the process can be increased and the quality can be improved and documented. The reason for this is the fact that inspection of the welding quality is time consuming and needs to be done by certified personal and furthermore repair work of defects is time consuming because each defect needs to be grinded off and redone.

Different sensing principles for arc welding give a range of various possibilities for automation of the arc welding process. An overview of the principles is given in Table. I, where " $\mathrm{X}$ " denotes the principles, which are suited and "(X)"denotes the ones, which are partly suited.

Detect part before welding is to determine the position and orientation of the part and hence the weld seam. Tracking during welding is to determine the position of the welding groove during process execution. Adaptive welding is to measure the groove geometry during welding in order to adjust the welding control variables ahead of welding. Process documentation is to document

Manuscript received October 29, 2013; revised December 9, 2013. the welding quality. Process control is to measure process states during welding in order to control the welding process.

TABLE I. ARC WELDING SENSING PRINCIPLES AND THEIR APPLICATION POSSIBILITIES.

\begin{tabular}{|c|c|c|c|c|c|}
\hline & $\begin{array}{l}\text { Detect } \\
\text { part } \\
\text { before } \\
\text { welding }\end{array}$ & $\begin{array}{l}\text { Tracking } \\
\text { during } \\
\text { welding }\end{array}$ & $\begin{array}{l}\text { Adaptive } \\
\text { welding }\end{array}$ & $\begin{array}{l}\text { Process } \\
\text { document } \\
\text { ation }\end{array}$ & $\begin{array}{l}\text { Process } \\
\text { control }\end{array}$ \\
\hline $\begin{array}{l}\text { Touch } \\
\text { sensor }\end{array}$ & $\mathrm{X}$ & & & & \\
\hline $\begin{array}{l}\text { Arc } \\
\text { sensor }\end{array}$ & & $X$ & $(\mathrm{X})$ & $X$ & \\
\hline $\begin{array}{l}\text { Laser } \\
\text { scanner }\end{array}$ & $X$ & $X$ & $X$ & $X$ & \\
\hline $\begin{array}{l}\text { Vision of } \\
\text { part }\end{array}$ & $\bar{X}$ & $\bar{X}$ & $\bar{X}$ & & \\
\hline $\begin{array}{l}\text { Vision of } \\
\text { process }\end{array}$ & & & $(\mathrm{X})$ & $\mathrm{X}$ & $X$ \\
\hline
\end{tabular}

The touch sensor, arc sensor, laser scanner and vision of part are all industrial products [1], whereas vision of process is mainly a research topic and investigated in this paper.

A control system for arc welding was developed and based on vision to monitor the arc during process execution in order to give information about the process state. This information is an indirect indication of the quality achieved at different positions during welding. It was applied to document the quality during process execution in a closed loop control system. The control loop was based on the adjustment of input process variables to keep the welding process in a state, where good quality was achieved. The approach of monitoring the arc was done by identifying the brightest and thereby the most robust source of light in the process. It is opposite to other approaches where light from the arc is filtered out to monitor the weld pool. Four of these approaches are described in the following review.

Measurement of weld pool light: [2] and [3] use a CCD camera system and filters to detect weld pool geometry 
and root gap for GTAW. Control with fuzzy logic and neural network is applied to control the correct weld pool geometry and weld penetration.[4]measures light from the backside of the weld pool and applies a fuzzy control to control the welding speed in order to secure correct weld penetration.[5]applies an optical sensor to detect the resonance frequency of the weld pool for TIG welding. The signal is treated in a fuzzy control to set the voltage and travel speed in order to control the weld penetration.[6]uses a CCD camera with filters to monitor the weld pool. The images are processed to give input for controlling the weld face width.

Measurement of workpiece radiation: [7] detects the temperature distribution of the workpiece surface with a CCD camera. The measurement is applied to control the travel speed and weaving, which in turn is to secure the correct temperature distribution and hence the desired microstructure.

Measurement of wire: [8] uses a high speed camera and stroboscopic light to detect the wire and applies a state space model to control the heat input.

Approaches of measuring emitted light from the arc are given in the literature. The measurement is done by a spectrum analysis. Measurement of the light spectrum: In [9] the emitted light from the arc plasma is analysed spectroscopic ally for wavelengths of argon and copper and by high speed camera images. The analysis concludes about the plasma arc and droplet formation and it is used for controlling the welding power supply. [10] is also measuring wavelength from the arc plasma and the afterwards analysis detects abnormalities of the arc, which are possibly resulting in welding defects. [11] applies a photodiode to monitor the arc spectrum and then treats the data to detect defects.

This paper describes a different approach to monitor the welding process compared to the before mentioned approaches. It is because in this work the position of the arc was detected and applied to process control.

\section{THEORY}

The welding process emits light in a wide range of wavelengths. The emission from the arc is mainly caused by the electrical current in the protection gas, see Fig. 1.

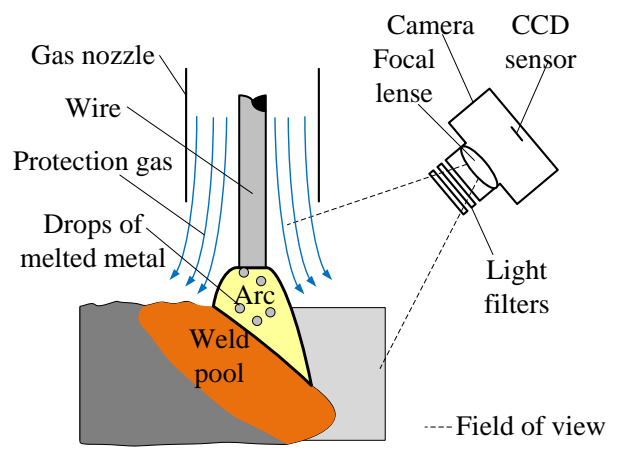

Figure 1. Monitoring the welding process.

The light is emitted from excited electrons in the protection gas, which emits light in narrow bands in the line spectra. The spectrum emitted depends on the protection gas composition. Argon is a commonly used protection gas component for welding and it has many emitting wavelengths with high intense emissions around $800 \mathrm{~nm}$ and 920 nm, see Fig. 2.

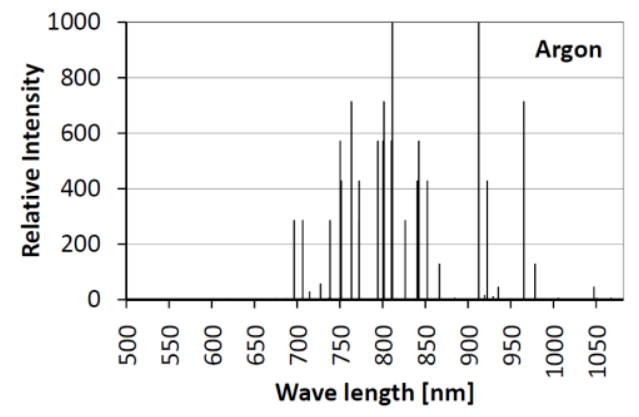

Figure 2. Emission spectra of argon above $500 \mathrm{~nm}$.[12]

The melted metal in the weld pool and wire emits light because of heat radiation with continuous wavelengths in a broader range than the light from the protection gas, which has narrow intensity peaks, as can be seen in Fig. 2. Melted metal in the weld pool reflects the light from the process and it gives intense spots of reflected light. Furthermore the welding process is changing fast with continuous supply of drops of melted metal to the weld pool and spatters, which causes poor image quality for a camera with a standard frame rate. By these reasons it is necessary to set up the vision system to monitor the wavelength of the strongest continuous light source, which is the arc. Disturbances from other light sources should then be cut out.

A vision system with a long opening time and light filters was designed to monitor the arc. The purpose of the long opening time was to reduce noise from drops and spatters, which are fast moving objects causing high light intensity for a short time. Applying filters in front of the camera filters the light out so that the camera is not overexposed. Furthermore, wavelengths in certain regions of the spectrum are reduced to capture only the wavelengths of interest from the arc:

- One filter reduces the general light to the camera, which is necessary because of the long opening time.

- The other band pass filter allows only light in a narrow band, where the protection gas in the arc has strong emitting wavelengths. In the case of a protection gas with high argon content only wavelengths of around $800 \mathrm{~nm}$ are chosen to be passed through, see Fig. 2. This excludes most of the light emission from the melted metal in the weld pool.

A CMOS camera was chosen to avoid vertical smear from overexposing of bright light caused by the arc. The image size was $491 \times 656$ pixels in 8 bit, which was a sufficient resolution for this application.

\section{Even Excess Penetration}

Weld joint with a varying root gap and no backing is a common weld type in the industry, e.g. for joining pipe branches and for joining plates in large steel constructions. It is also a difficult weld joint to 
manufacture and to obtain certain quality grades according to [13]. For weld joints without backing it is important to produce a back bead with a certain geometrical shape, obtain interfusion and avoid welding defects. Often the weld face is not so important because the additional weld seams have to be added.

The proposed system was designed to secure an even excess penetration of the back bead by controlling the displacement of the arc front and thereby indirectly controlling the weld pool position during the process, see Fig. 3.
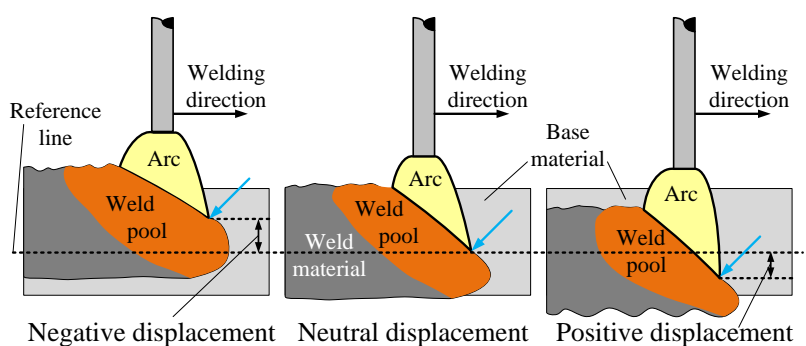

Negative displacemen

Neutral displacement

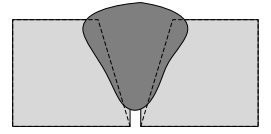

Excess penetratio high
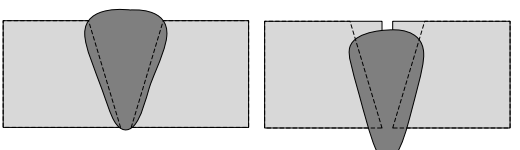

low
Figure 3. The displacement of the arc front, marked by the blue arrow and measured from the reference line, and its relationship to the excess penetration.

The hypothesis was as follows. If a negative displacement was measured then the weld pool was located too high. In this case the power had to be increased to melt the weld pool deeper into the groove and the travel speed has to be increased to lower the amount of weld material per millimetre weld. If a positive displacement was observed the weld pool was located too low. In this case the power had to be decreased to avoid overheating the weld pool and making it fall through the groove and the travel speed had to be decreased to allow more material to build up in the weld pool.

In order to implement the proposed method a closed loop control was applied and based on fuzzy control. Fuzzy control was chosen because the exact knowledge about controlling the process was unknown and instead it was based on expert rules. These rules can be applied and tuned during the testing phase to prove the concept.

\section{EXPERIMENTAL SETUP}

An experimental setup consists of the equipment and its configuration listed in Table II and shown in Fig. 4.

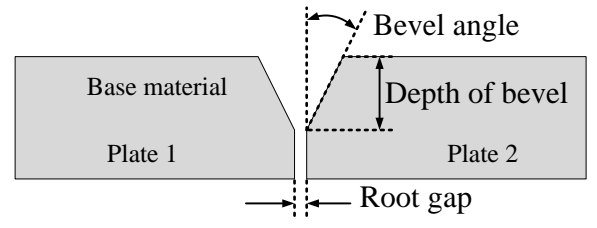

Figure 4. Cut section of workpiece geometry.
TABLE II. SPECIFICATION OF EQUIPMENT

\begin{tabular}{|c|c|}
\hline Welding machine & Migatronic Flex4000 \\
\hline Gas mixture & $92 \%$ argon and $8 \% \mathrm{CO}_{2}$ \\
\hline Gas flow rate & 27 liter/minute \\
\hline Gas nozzle diameter & $15 \mathrm{~mm}$ \\
\hline Wire type & OK Autorod 12.51 \\
\hline Wire diameter & $1 \mathrm{~mm}$ \\
\hline Contact tube to workpiece distance & $12 \mathrm{~mm}$ \\
\hline Robot & ABB IRB140 \\
\hline Torch angle & $\begin{array}{l}\text { Top down, } \\
\text { perpendicular to workpiece }\end{array}$ \\
\hline Camera & Basler A601f \\
\hline Light filters & $\begin{array}{ll}\text { 1. } & 665 \mathrm{~nm} \text { long pass filter } \\
& {[14]} \\
\text { 2. } & 810 \mathrm{~nm} \text { center } \\
& \text { wavelength and } 10 \mathrm{~nm} \\
& \text { full width-half } \max [15]\end{array}$ \\
\hline Workpiece & Steel S235 \\
\hline Orientation & Horizontal \\
\hline Dimensions of plate 1 and 2 & $\begin{array}{l}\text { Length } 300 \mathrm{~mm} \\
\text { Width } 50 \mathrm{~mm} \\
\text { Thickness } 10 \mathrm{~mm}\end{array}$ \\
\hline Weld joint & Butt-joint with a V-groove \\
\hline Bevel angle plate 1 and 2 & 45 degrees \\
\hline Depth of bevel plate 1 and 2 & $4 \mathrm{~mm}$ \\
\hline PC & HP Z400, 2.66 GHz Intel Xeon \\
\hline Data acquisition & $\begin{array}{l}\text { National Instruments } \\
\text { BNC2120 }\end{array}$ \\
\hline
\end{tabular}

Fig. 5. shows the physical setup with the camera angledapproximately30 degrees in relation to the workpiece. This angle ensures that the arc is monitored from the front side, where the bottom position of the arc can be determined.

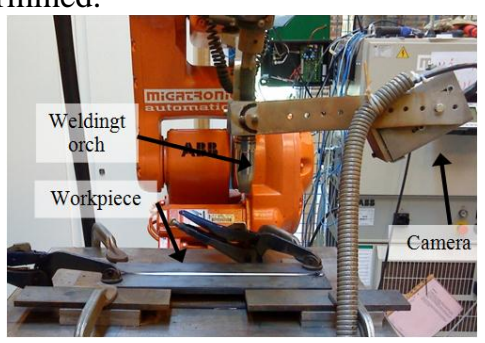

Figure 5. Setup of the physical system.

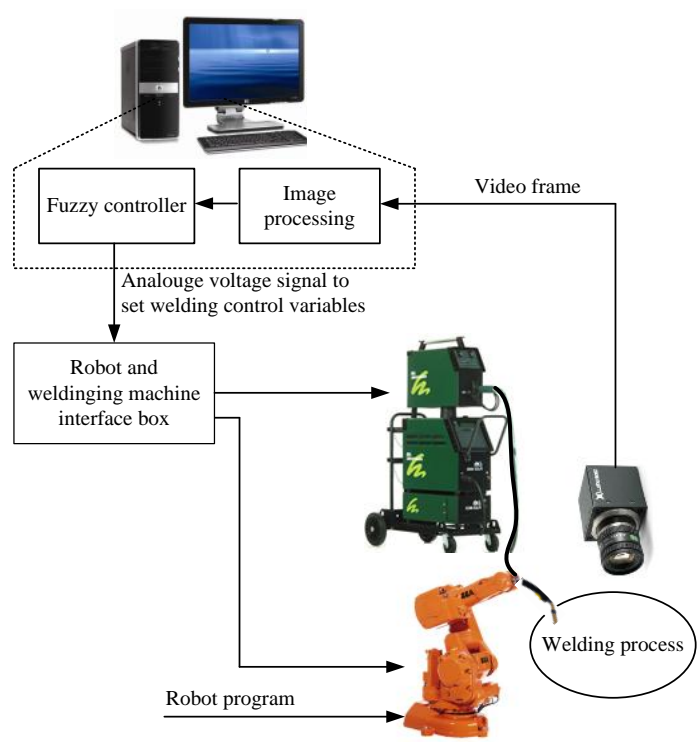

Figure 6. System setup. 
The setup of the entire system is illustrated in Fig. 6, where the video frame from monitoring the welding process is executed on a PC with the controller implemented in LabView. Analogue control signals are sent from the controller to set the welding control variables for the welding machine and robot.

The loop rate of the system was controlled by the time for image processing, which was around 11images per second. The camera was adjusted with a gain, shutter and brightness to take images with a clearly visible white arc and where the light from other sources resulted in grey and dark pixels in the image.

\section{A. Image Processing}

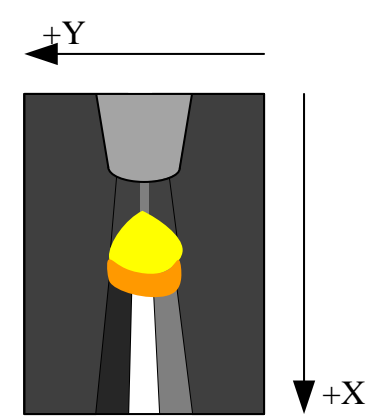

a) Illustration of camera image and coordinate system.

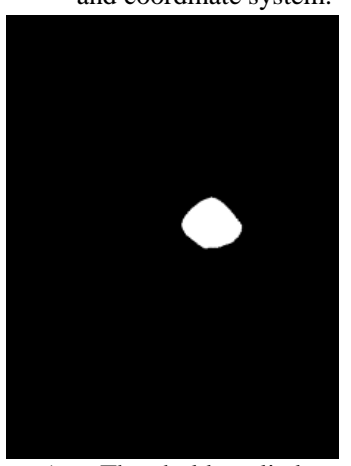

c) Threshold applied.

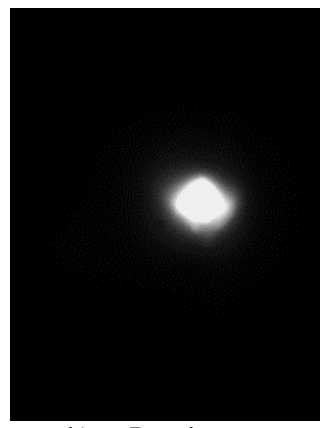

b) Raw image.

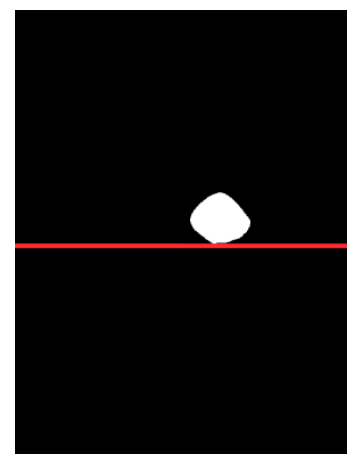

d) Red line indicates measurement of bottom coordinate.
Figure 7. Principle of the image processing carried out.

The image processing was done as illustrated in Fig. 7. Illustration a) is the setup seen from the camera, which takes an image illustrated in b) during the process execution. In c) a threshold was set to assign all grey pixels to either black or white. In the experiments the lower threshold was 210 and the upper one was 255 . Afterwards, in d), a function detects the bottom most white pixel, and the $\mathrm{x}$-value of this pixel, called the bottom coordinate, is an output of the image processing.

\section{B. Fuzzy Control of Even Excess Penetration}

A bottom coordinate reference has to be found for each welding setup and be a reference for a good quality weld. In this work it was done experimentally. The bottom coordinate reference was compared to the measured bottom coordinate and the error was used as an input to the Fuzzy controller in the implemented closed loop control, see Fig. 8. The Fuzzy controller then generates control signals to control the physical welding process.
Fixed control variables, equipment and workpiece parameters

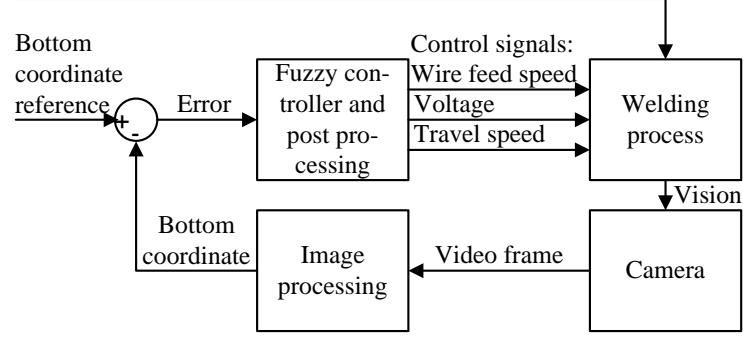

Figure 8. The implemented closed loop control.

The Fuzzy control works as illustrated in Fig. 9. The calculated error was fuzzificated to the linguistic input variables after a degree of membership, which was set and tuned based on experience obtained during experimentation, see Fig. 10.

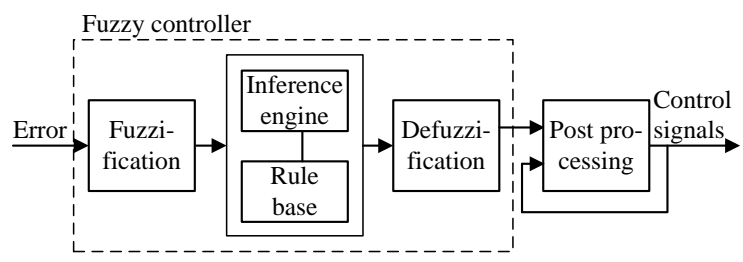

Figure 9. Fuzzy controller implemented after [16].

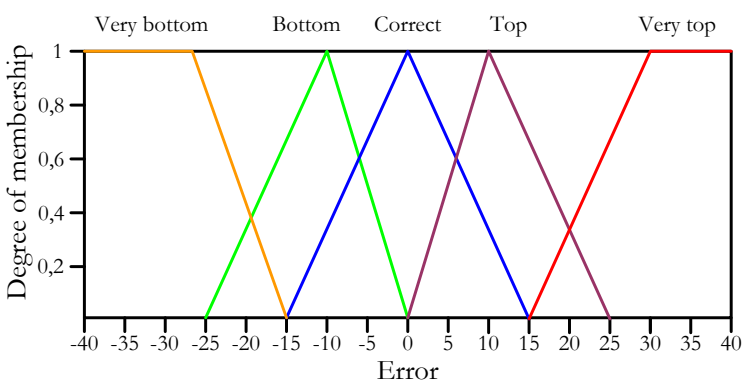

Figure 10. Fuzzification.

The linguistic input variables were then transformed in a designed rule base to give linguistic output variables.

Rule base of the fuzzy controller:

1) If Error Is Very bottom Then output Is Very negative

2) If Error Is Bottom Then output Is Negative

3) If Error Is Correct Then output Is Zero

4) If Error Is Top Then output Is Positive

5) If Error Is Very top Then output Is Very positive

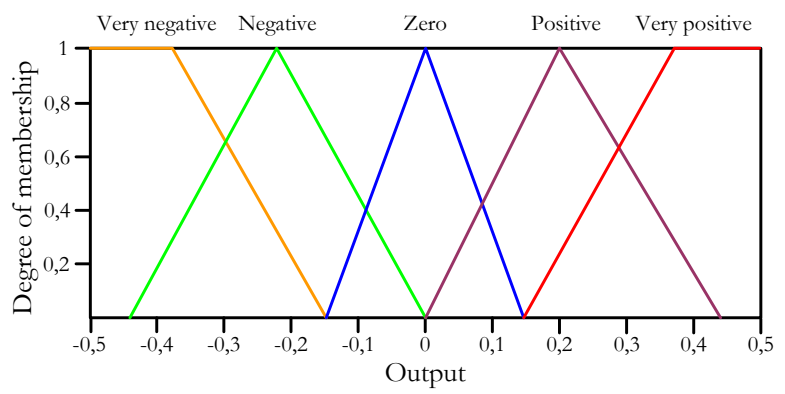

Figure 11. Defuzzification.

The linguistic output variables were defuzzified to an output, which was set and tuned based on experience 
obtained during experimentation, see Fig. 11. The defuzzification gives an output in the range $[-0.5 ; 0.5]$.

The output was then post processed to produce control signals to the physical process. Three welding control variables, which have an impact on the excess penetration were selected; wire feed speed, voltage and travel speed. The values of these control variables were set from the output of the defuzzification by the formula:

Wire feed $\operatorname{speed}(t)=$ Wire feed $\operatorname{speed}(t-1)+$ Output $(t)$ $\operatorname{Voltage}(\mathrm{t})=\operatorname{Voltage}(\mathrm{t}-1)+\operatorname{Output}(\mathrm{t}) \cdot 0.25$

Travel $\operatorname{speed}(t)=$ Travel $\operatorname{speed}(t-1)+\operatorname{Output}(t) \cdot 0.62$

When the output is negative then the wire feed speed is reduced and it results in a reduced current to decrease the heat input to the welding process. The voltage has to follow the current for arc welding. When the wire feed speed is reduced then the welding speed has to be decreased to compensate for a lower material input. When the output is positive it is the opposite reaction.

In this work the ratio between the control signals in the formula was not tuned towards the optimal welding quality.

\section{RESULTS}

An experimental setup in a reference experiment was made to test the difference between welding without control and welding with control. The root gap in the experiments was linearly increased from $0 \mathrm{~mm}$ at the start position on the workpiece to $3 \mathrm{~mm}$ at the end position on a $300 \mathrm{~mm}$ long workpiece shown in Fig. 12. and Fig. 13. The travel distance is given in centimetre and measured on the scale bar at the bottom of the image, starting at zero on the left hand side of the image. It is clearly seen that the weld with the controller travels $65 \mathrm{~mm}$ further than without controller.

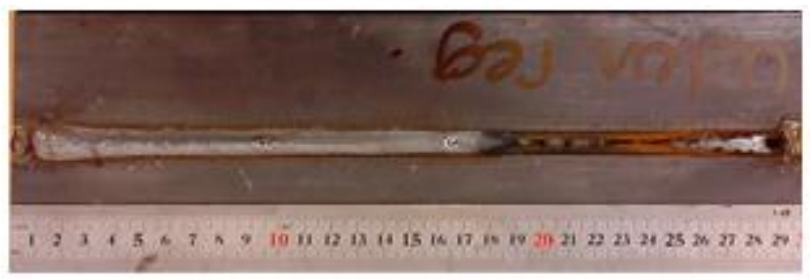

Figure 12. Welding result without controller reaches $175 \mathrm{~mm}$.

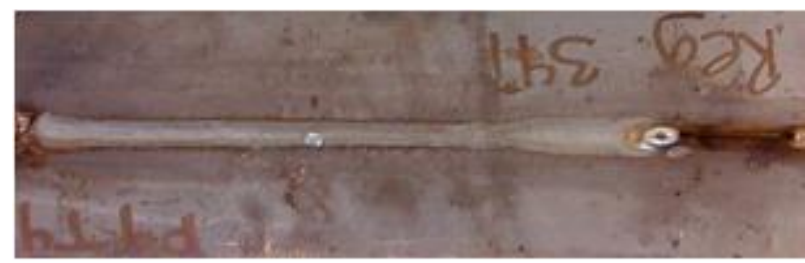

Figure 13. Welding result with controller reaches $240 \mathrm{~mm}$.

Fig. 14 shows the result of the investigation of weld face width, which is continuously decreased for the reference welding experiment. At $125 \mathrm{~mm}$ travel distance the face gap width becomes wider than the weld face width, which introduces a notch that can reduce the weld strength. The notch defect occurred at a root gap of 1.25 $\mathrm{mm}$ and when the root gap was $1.75 \mathrm{~mm}$ the weld pool fell through the root gap.

The experiment with the controller keeps a steady weld face width after $50 \mathrm{~mm}$ travel distance, used as a start-up of the weld. At $170 \mathrm{~mm}$ travel distance the controller starts to increase the value of weld face width to avoid the weld face width becoming narrower than the face gap width. The controller was not tuned to the right level, which can be seen in Fig. 14 between 190 and $240 \mathrm{~mm}$ trawled distance. The control weld face width was increased more than necessary in relation to the face gap width to avoid the occurrence of a notch. With the controller it was possible to weld a varying root gap between 0 and 2.4 $\mathrm{mm}$ and without a notch at the weld face.
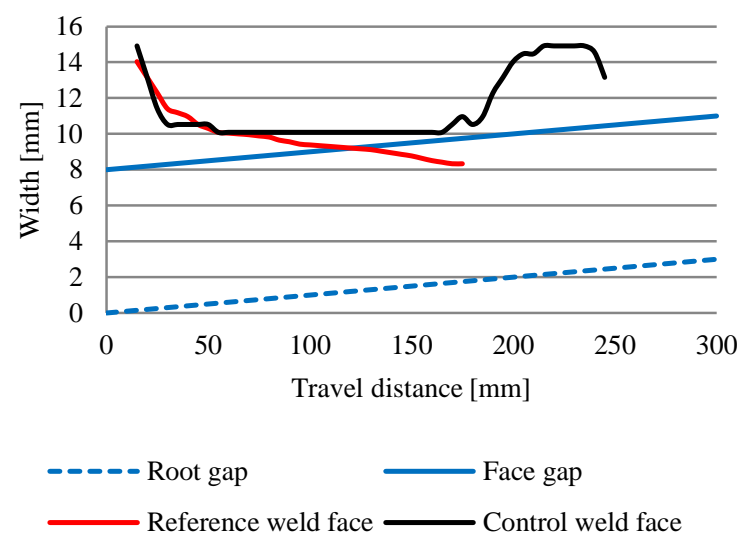

Figure 14. Weld face widths for the reference experiment and the experiment with the controller. The obtained weld face widths are compared to the groove width for the root gap and face gap.

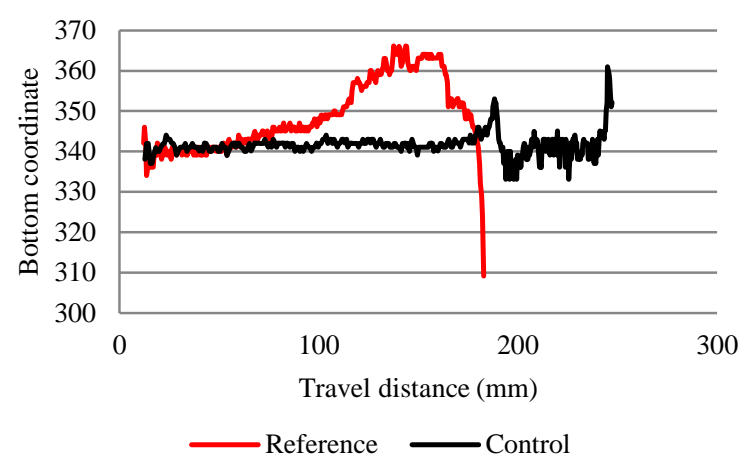

Figure 15. Bottom coordinates.

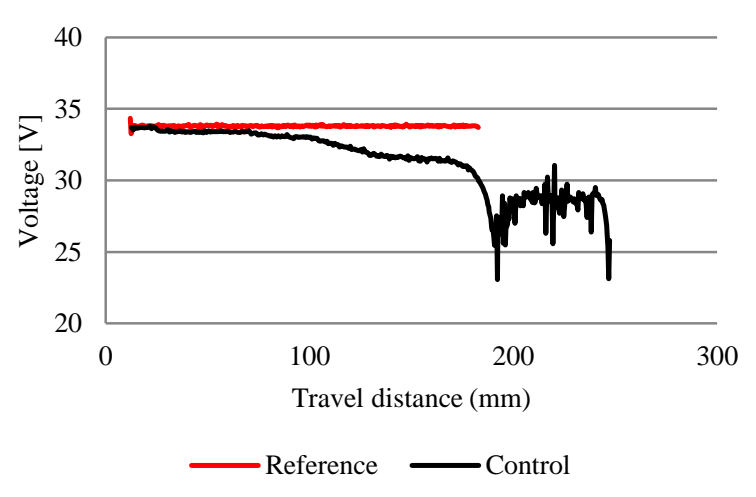

Figure 16. Voltages. 
The bottom coordinate was measured for the reference experiment and for the experiment with the applied controller. The results are presented in Fig. 15 and show that the bottom coordinate is varying for the reference experiment and for the other experiment the bottom coordinate is steadier. In Fig. 16 to Fig. 18 the constant control signals in the reference experiment are shown in relation to the control signals when applying the fuzzy controller.

For the part of the weld from the start to around 180 $\mathrm{mm}$ travel distance the bottom coordinate is kept steady when applying the controller, whereas the bottom coordinate has a positive displacement into the groove in the reference experiment. Until $180 \mathrm{~mm}$ travel distance the controller makes a slight adjustment of the control signals. At $175 \mathrm{~mm}$ travel distance the reference cannot be welded, whereas the controller adjusts the control signals to keep on welding until240mm travel distance.

For the travel speed a lower limit was set to $4 \mathrm{~mm} / \mathrm{sec}$ to avoid the process being carried out outside a decent process window.

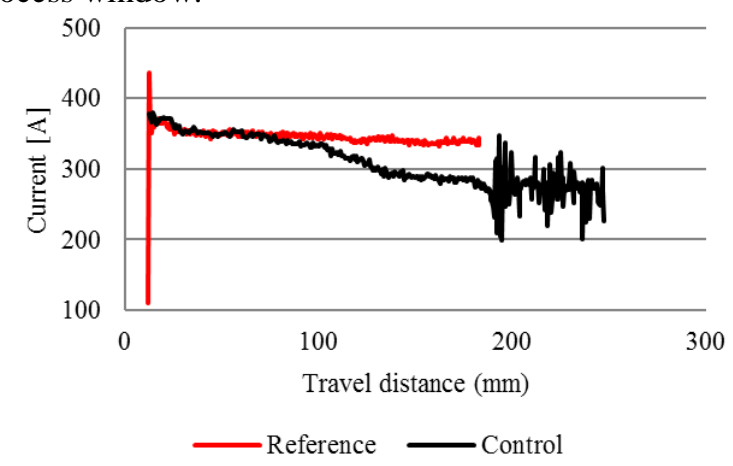

Figure 17. Currents.
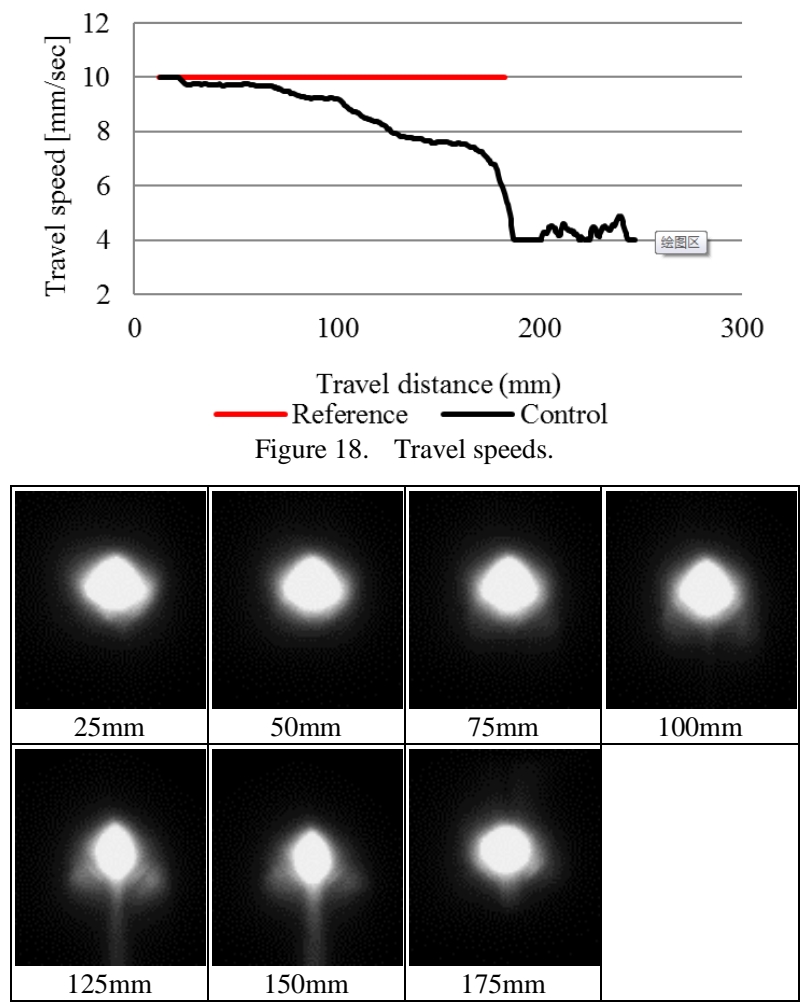

Figure 19. Arc images taken along the travel distance without control.
Raw arc images are equally cropped to enlarge the arc. It was done to show the changes for the reference experiment in Fig. 19 and for the experiment with the controller, shown in Fig. 20.

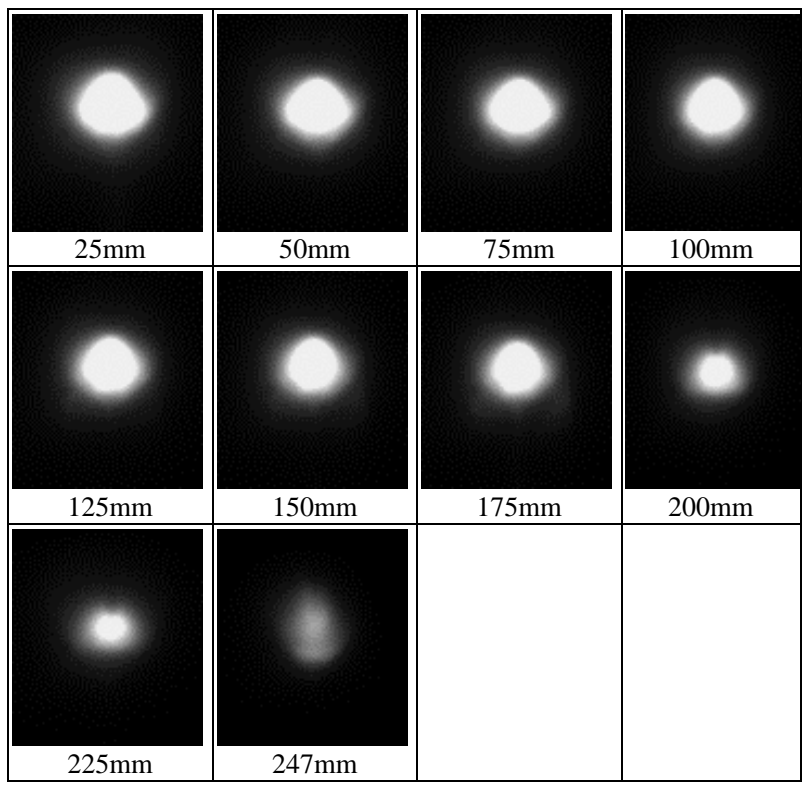

Figure 20. Arc images taken along the travel distance with control.

For the arc images without control the position of the arc's bottom coordinate slightly moves downwards for the first $150 \mathrm{~mm}$ travel distance. With control the arc images are almost kept with a steady position of arc's bottom coordinate for the entire welding distance. For the first $175 \mathrm{~mm}$ travel distance the controller slightly regulates for the increasing root gap, but after $175 \mathrm{~mm}$ travel distance the arc shape changes because the controller drastically reduces the wire feed speed and voltage to avoid overheating the weld pool and prevent excess penetration.

\section{CONCLUSION}

It has been demonstrated that vision of the arc is a robust source of on-line gathered process information about the state of the welding process. The arc vision can be applied to document and control the welding quality.

A reference gas metal arc weld with fixed welding control variables was carried out for a Butt-joint with a $\mathrm{V}$-groove and an increasing root gap. Welding defects due to notch occurred when the root gap was increased to $1.25 \mathrm{~mm}$ and the weld pool fell through the root gap when it was $1.75 \mathrm{~mm}$ width. A gas metal arc welding setup was equipped with the arc vision setup and a closed loop fuzzy control. With this setup it was demonstrated that a varying root gap between 0 and $2.4 \mathrm{~mm}$ could be controlled by monitoring the position of the bottom of the arc. No defects because of notch occurred.

Future work:

- Tune the controller to work in a larger process window and with an improved welding quality.

- Perform more measurements of the arc to give input to a more advanced controller. 
- Adjust the bottom coordinate reference automatically.

- Extend this work to other weld joints, workpiece thicknesses, protection gases and materials.

\section{REFERENCES}

[1] Sensor based adaptive arc welding - Robotic automation of irregular. Inconsistent and Difficult to Access Joint Interfaces. ABB. [Online]. Available: http://www05.abb.com/global/scot/scot241.nsf/veritydisplay/8ca2 d32ae35d123cc125799f00592be4/\$file/sensor\%20based\%20adapt ive $\% 20$ arc $\% 20$ welding\%20white\%20paper.pdf

[2] H. Chen, F. Lv, T. Lin, and S. Chen, "Closed-loop control of robotic arc welding system with full-penetration monitoring," Journal of Intelligent and Robotic Systems, vol. 56, pp. 565-578, 2009.

[3] S. B. Chen, Y. Zhang, T. Qiu, and T. Lin, "Robotic welding system with vision-sensing and self-learning neuron control of arc welding dynamic process," Journal of Intelligent and Robotic Systems, vol. 36, pp. 191-208, 2003.

[4] A. S. Baskoro and R. Masuda, "An application of genetic algorithm for edge detection of molten pool in fixed pipe welding," International Journal of Advanced Manufacturing Technology, vol. 45, pp. 1104-1112, April 2009.

[5] D. A. Hartman, D. R. DeLapp, G. E. Cook, and R. J. Barnett, "Intelligent fusion control throughout varying thermal regions," in Proc. 34th Annual Meeting - IEEE Industry Applications Society, October 1999, pp. 1-10.

[6] W. Lucas, D. Bertaso, G. Melton, J. Smith, and C. Balfour, "Realtime vision-based control of weld pool size," Welding International, vol. 26, no. 4, pp. 243 -250, 2012.

[7] H. C. K. Orye, "Sensor based welding automation modelling: Including a special developed low-cost temperature," Ph.D. dissertation, Dept. of Production, Aalborg Univ., Aalborg, Denmark, 2005.

[8] Z. Bingul and G. E. Cook, "A real-time prediction model of electrode extension for GMAW," IEEE/ASME Transactions on Mechatronics, vol. 11, no. 1, pp. 47-54, February 2006.

[9] G. Gott, H. Schopp, F. Hofmann, and G. Heinz, "Improvement of the control of a gas metal arc welding process," Measurement Science and Technology, vol. 21, pp. 1-7, 2010.

[10] D. Naso, B. Turchiano, and P. Panteleo, "A fuzzy-logic based optical sensor for online weld defect-detection," IEEE Transactions on Industrial Informatics, vol. 1, November 2005.

[11] J. Mirapeix, A. Cobo, O. M. Conde, C. Jaúregui, and J. M. LópezHiguera, "Real-time arc welding defect detection technique by means of plasma spectrum optical analysis," NDT \& E International, vol. 39, no. 5, pp. 356-360, July 2006.

[12] NIST Atomic Spectra Database Lines Form. [Online]. Available: http://physics.nist.gov/Physrefdata/ASD/lines_form.html

[13] Welding - Fusion-welded joints in steel, nickel, titanium and their alloys (beam welding excluded) - Quality levels for imperfections (ISO 5817:2003), DS/EN ISO 5817, 2. ed., 2005.

[14] RG-665 Long Pass Filter, Edmund Optics. [Online]. Available: http://www.edmundoptics.com/techsupport/resource_center/produ ct_docs/curv_45070.pdf

[15] 810nm CWL. 10nm Bandwidth, Edmund Optics [Online], Available:http://www.edmundoptics.com/techsupport/resource_ce nter/product_docs/curv_67849.pdf
[16] J. Jantzen, "Design of fuzzy controllers," Tech. Report no. 98-E 864 (Design), Technical University of Denmark, September 30 1999.

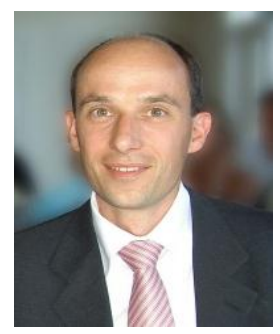

Morten Kristiansenis associate professor in the Department of Mechanical and Manufacturing Engineering, Aalborg University, Denmark, where he is teaching and researching in the area of manufacturing technology, robotics and process automation. Currently his research is in automation and modeling of the laser cutting and welding process. Previously Morten Kristiansen has worked at Aalborg University and received in 2007 his Ph.D. degree, in the field of modeling of the welding process using different knowledge sources and artificial intelligence.

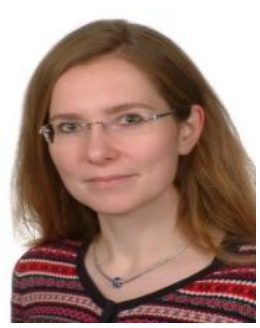

Ewa Kristiansenis an assistant professor in the Department of Mechanical and Manufacturing Engineering at Aalborg University, Denmark. In 2005 she received her MSc in the Department of Electrical Engineering at Warsaw University of Technology, Poland, and MSc in the Department of Electronic Systems at Aalborg University, Denmark. In 2007 she was a visiting graduate student at The Robotics Institute at Carnegie Mellon University, USA She received her Ph.D. degree from the Department of Production at Aalborg University in 2009. Her research interests include scheduling of the industrial robots and design and control of the autonomous mobile field robots.

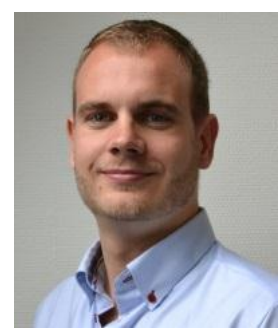

Casper Houmann Jensen is project engineer in Aalborg Engineering, Denmark, where he is working with specifying and purchasing large components for boilers plants. Previously Casper Houmann Jensen worked with process automation for Siemens Wind Power, and he received his master's degree in 2010 from Aalborg University with a specialization in welding automation using vision technology and fuzzy control.

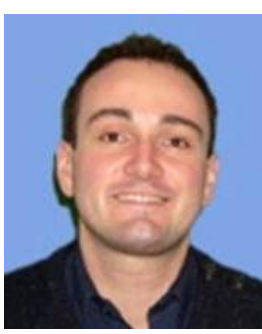

René Slot Christensen is a Quality Engineer in Novo Nordisk A/S in Hillerød, Denmark, where he currently works with suppliers of plastic components to Novo Nordisk products. René works on improving the quality and ensuring delivery of several components through process and material optimization. René Slot Christensen graduated in 2010 from Aalborg University with a degree in Manufacturing Technology. After graduation he started working at Siemens Wind Power in Aalborg, Denmark, where he worked as project manager and participant in areas such as Risk Management, Ultrasonic scanning of glass-fibre reinforced polymers and process optimization. 